\title{
AÇÕES AFIRMATIVAS NA UNIVERSIDADE: RETRATOS DE UMA PESQUISA SOBRE A INSERÇÃO DA POLÍTICA DE COTAS EM UMA FACULDADE PÚBLICA DE DIREITO
}

\author{
Erli Sá dos Santos \\ Matheus Guarino Sant'Anna Lima de Almeida \\ Heloisa de Faria Pacheco
}

\section{INTRODUÇÃO}

Este artigo é resultado de pesquisa realizada de 2015 a 2016, acerca da implementação e recepção das ações afirmativas na Faculdade de Direito da Universidade Federal Fluminense (UFF). Mais precisamente, a pesquisa buscava investigar tantos dados sobre o sistema de ações afirmativas implementado na UFF, quanto dados objetivos relacionados às ações afirmativas na Faculdade de Direito dessa universidade, assim como dados subjetivos ligados às percepções dos diferentes seguimentos da comunidade acadêmica dessa faculdade quanto à implementação das ações afirmativas, compreendendo alunos de graduação, pós-graduação, professores e servidores.

O sistema de reserva de vagas por cotas para o ingresso no ensino superior em universidades federais foi implementado em seu modelo atual por meio da Lei n. 12.711/2012, a chamada Lei de Cotas. Anteriormente a ela, algumas universidades federais já adotavam outros modelos de ações afirmativas para grupos minoritários, por critérios de renda ou raça e etnia. Na UFF, havia anteriormente um sistema de acréscimo de pontos na nota do vestibular para os autodeclarados pretos e pardos, sistema esse que foi abandonado com a implementação da lei atual.

Pela Lei de Cotas, são reservados "[...] em cada concurso seletivo para ingresso nos cursos de graduação, por curso e turno, no mínimo 50\% 
(cinquenta por cento) de suas vagas para estudantes que tenham cursado integralmente o ensino médio em escolas públicas." (BRASIL, 2012a). Desse percentual, $50 \%$ deverão ser reservados aos estudantes oriundos de famílias com renda igual ou inferior a um salário-mínimo e meio. Ainda, desse percentual, serão reservadas vagas aos autodeclarados pretos, pardos, indígenas e pessoas com deficiência na população da Unidade da Federação onde a universidade estiver situada, de acordo com o censo da Fundação Instituto Brasileiro de Geografia e Estatística (IBGE). Os outros $50 \%$ de vagas do total serão destinados aos estudantes não cotistas, ou seja, aqueles que fazem o processo seletivo em ampla concorrência.

Dessa maneira, a reserva é realizada atualmente em quatro modalidades, de acordo com o artigo 14 da Portaria n. 18, de 11 de outubro de 2012, do Ministério da Educação (MEC) (BRASIL, 2012b), que regula a aplicação da Lei de Cotas. A primeira modalidade (chamada L1) engloba os candidatos com renda familiar bruta per capita igual ou inferior a um salário mínimo e meio que tenham cursado integralmente o ensino médio em escolas públicas. A segunda modalidade (L2) engloba os candidatos autodeclarados pretos, pardos ou indígenas, com renda familiar bruta per capita igual ou inferior a um salário mínimo e meio e que tenham cursado integralmente o ensino médio em escolas públicas. A terceira modalidade (L3) engloba os candidatos que, independentemente da renda, tenham cursado integralmente o ensino médio em escolas públicas. $E$ a quarta modalidade (L4) engloba os candidatos autodeclarados pretos, pardos ou indígenas que, independentemente da renda, tenham cursado integralmente o ensino médio em escolas públicas.

De acordo com o artigo 8o do Decreto n. 7.824/2012 (BRASIL, 2012c), a implementação de $50 \%$ de reserva de vagas se deu de maneira progressiva, sendo aplicadas $12,5 \%$ de reserva de vagas a cada ano, até agosto de 2016, quando houve a integralização da reserva de vagas. Dessa maneira, os períodos mais iniciais apresentam maior quantidade de cotistas do que os períodos mais avançados (aqueles próximos de concluir o curso).

A motivação inicial da pesquisa foi realizar uma investigação ampla sobre a inserção e recepção do sistema de reserva de vagas na Faculdade de Direito da UFF, investigando como a comunidade acadêmica 
entendia as mudanças na faculdade a partir de sua implementação, relacionando possíveis resultados dessa política pública a questões como o combate racismo, a inclusão, à diversidade e a formação educacional do profissional de Direito.

A pesquisa partiu de um entendimento pressuposto no senso comum de que a Faculdade de Direito é considerada um ambiente geralmente elitista, conservador, opressor e racista (percepção essa que acabou por ser corroborada pelos diversos depoimentos trazidos na pesquisa), e se justifica pela necessidade de gerar dados sobre a situação dos ingressantes por ações afirmativas na Faculdade de Direito, sobre seus sentimentos de pertencimento, e sobre a percepção de toda a comunidade acadêmica acerca de temáticas ligadas às ações afirmativas e ao racismo, além das mudanças que a Faculdade teria passado com o decorrer da implementação do sistema de cotas.

A pesquisa foi realizada ao longo dos anos de 2015 e 2016, sob a coordenação do professor Delton Meirelles. Participaram da pesquisa, de início, alunos voluntários, e ao longo de 2016, durante os períodos de 2016.1 e 2016.2, alunos inscritos na disciplina optativa "Grupo de pesquisa em Direitos Humanos, Governança e Poder".

O presente artigo traz alguns dados e reflexões sobre a pesquisa, sendo dividido em quatro partes. Na primeira, será explicada a construção da pesquisa, a maneira de coleta e interpretação de dados, e algumas reflexões sobre eles. Na segunda parte, serão expostos e analisados alguns dos dados objetivos coletados pela pesquisa, provenientes dos bancos públicos de dados da Universidade, oriundos de dados cedidos pela coordenação de curso da Faculdade de Direito, e coletados a partir dos questionários semiestruturados. A terceira parte realizará uma breve análise das respostas abertas dos questionários, sobre a percepção da comunidade acadêmica quanto ao sistema de cotas. Por fim o encerramento traz algumas reflexões sobre o silenciamento do debate acerca do racismo e das ações afirmativas, entendendo o silenciamento como a materialidade do silêncio. Tomando por base os referenciais teóricos da Análise de Discurso de matriz francesa, por meio dos conceitos desenvolvidos por Eni Orlandi (1995), será apresentado o resultado de um esforço interpretativo que buscou compreender os 
discursos apurados na pesquisa. Assim, com essa base teórica, o silêncio no contexto universitário representa uma categoria que significa, porque por trás dele há uma história, que possibilita sua compreensão.

\section{A CONSTRUÇÃO METODOLÓGICA DA PESQUISA}

Como colocado, a pesquisa foi realizada nos anos de 2015 e 2016 e contou com diversas etapas. A primeira etapa consistiu na coleta e tabulação objetiva de dados nos bancos públicos da UFF e de dados fornecidos pela Coordenação do Curso de Direito da UFF.

Primeiramente, foi realizado um mapeamento do corpo estudantil da UFF e das formas de ingresso dos estudantes de 2010 a 2015. Para o mapeamento, foram utilizados dados públicos da Coordenação de Seleção Acadêmica da UFF (COSEAC-UFF) e do SISU/ ENEM $^{1}$ do MEC. Esses dados foram cruzados com dados fornecidos pela Coordenação de Curso da Faculdade de Direito da UFF, que traziam informações como Coeficiente de Rendimento (CR) (média de notas do aluno ao longo do curso), trancamento e reprovação de disciplinas, idade, abandono, nota de ingresso no ENEM. Também foram obtidos dados gerais sobre notas de corte, notas na última chamada, desistência de vaga, cancelamento, ${ }^{2}$ porcentagem de alunos que continuam cursando o curso e os que estão com a matrícula trancada, sendo todos esses dados discriminados por semestre de ingresso e por forma de ingresso (cada tipo de reserva de vagas ou ampla concorrência). Esses dados, conforme será demonstrado, nos ajudaram a desfazer uma série de pré-concepções sobre o aproveitamento dos alunos ingressantes por ação afirmativa em comparação com os ingressantes por ampla concorrência, assim como mapear uma série de desafios para a concretização dos fins do sistema ações afirmativas.

\footnotetext{
${ }^{1}$ SISU é o Sistema de Seleção Unificada para o ingresso no ensino superior, generalizado para a maior parte das universidades brasileiras, por meio das notas obtidas no Exame Nacional do Ensino Médio (ENEM), realizado anualmente pelo Ministério da Educação (MEC).

${ }^{2}$ Os cancelamentos foram discriminados em trancamentos por indeferimento de avaliação socioeconômica, por alteração de matrícula, por mudança de curso, por rematrícula ou por solicitação oficial. Se realizados com os dados do ano de 2017, também haveria dados.
} 
A partir dessa etapa inicial, os pesquisadores envolvidos puderam discutir e elaborar as questões a constarem nos formulários que seriam distribuídos para a comunidade acadêmica, tomando como base as reflexões tiradas da análise dos dados coletados, e reflexões acerca da problemática das ações afirmativa das questões raciais e sociais internas à Faculdade de Direito e ao campo jurídico.

Em um segundo momento, então, foi realizada pesquisa por meio de questionários semiabertos, distribuídos por meio eletrônico, a serem respondidos pelos diversos setores da comunidade acadêmica. Dessa maneira, foram elaborados questionários diferentes para os alunos de graduação, ${ }^{3}$ para os alunos de pós-graduação, para os professores e para os servidores, além de um formulário específico para os graduandos

\footnotetext{
${ }^{3}$ A título de exemplo, o formulário dos graduandos (ingressantes por ampla concorrência ou por ação afirmativa) possuía onze perguntas objetivas e uma de resposta aberta. Todas as perguntas objetivas, com exceção das perguntas 4 e 8 , consistiam em uma afirmação, à qual se questionava o nível de concordância (concordo integralmente, concordo parcialmente, discordo parcialmente, discordo integralmente ou não tenho opinião formada). Eram elas: 2) Com relação à frase a Universidade deveria considerar exclusivamente o mérito intelectual como critério de acesso aos cursos de graduação; 3) Com relação à frase a Universidade deveria selecionar estudantes que representassem fielmente a diversidade econômica e étnica de nossa sociedade; 5) Com relação à frase reservar vagas para estudantes de baixa renda diminui a qualidade do Curso de Direito; 6) Com relação à frase reservar vagas para estudantes egressos de escolas pública (ensino médio) diminui a qualidade do Curso de Direito; 7) Com relação à frase reservar vagas para estudantes indígenas, negros e pardos; 9) Com relação à reserva de vagas para bolsas no Curso de Graduação em Direito da UFF (monitoria, extensão, PIBIC etc.); 10) Com relação a reserva de vagas para ingresso nos Cursos de Pós-graduação stricto sensu (mestrado e doutorado) vinculados à Faculdade de Direito da UFF; 11) Com relação à reserva de vagas nos concursos para professor efetivo do Curso de Direito da UFF: diminui a qualidade do Curso de Direito; e 12) Com relação à reserva de vagas nos concursos para carreiras jurídicas (magistratura, Ministério Público, Defensoria Pública, Advocacia Pública etc.). As duas perguntas que possuíam opções de respostas diferentes eram: 4) Em sua opinião, a reserva de vagas por política de ação afirmativa (pode marcar mais de uma opção), com as seguintes possibilidades de resposta: a) Não deveria existir; b) Deve incluir estudantes que cursaram ensino médio em escolas públicas; c) Deve incluir estudantes pobres; d) Deve incluir estudantes por critérios étnicos (indígenas, negros e pardos); e) Não tenho opinião formada; e 8) Em sua opinião, qual seria um percentual justo de reserva de vagas, no Curso de Direito da UFF, para políticas de ação afirmativa?, com as seguintes possibilidades de resposta: a) $0 \%$ (todos devem disputar em igualdade de condições); b) $1 \%$ a $10 \%$; c) $11 \%$ a $25 \%$; d) $26 \%$ a $50 \%$; e) $51 \%$ a $75 \%$; f) $76 \%$ a $90 \%$; g) $91 \%$ a $99 \%$; h) $100 \%$; i) Não tenho opinião formada. A pergunta aberta era: Qual é a sua opinião sobre reserva de vagas para o Curso de Direito da UFF, em razão de políticas de ação afirmativa (cotas). Os outros formulários distribuídos aos professores, servidores e estudantes de pós-graduação traziam perguntas sobre os conhecimentos, percepções e opiniões dessas pessoas acerca do sistema de cotas, sua inserção na Faculdade de Direito, e sobre outras políticas de ações afirmativas.
} 
ingressantes por reserva de vagas. Os questionários respondidos pelos ingressantes por ação afirmativa possuíam também perguntas de caráter socioeconômico, e perguntas que buscavam as experiências e anseios desses alunos sobre o Curso de Direito e a Universidade. ${ }^{4}$ Depois da distribuição dos questionários, foram realizados também, em dois encontros, grupos focais com os alunos cotistas, onde, reunidos, conversaram sobre o sistema de cotas, sobre racismo, sobre a Faculdade de Direito e sua experiência nela.

\footnotetext{
${ }^{4}$ Constavam como perguntas específicas para este questionário: 1) Em qual escola você concluiu o ensino médio? (resposta aberta); 2) Em que ano você concluiu o ensino médio? (resposta aberta); 3) Você frequentou algum curso preparatório para o ENEM? (com as possíveis respostas: a) não; b) Sim, curso preparatório gratuito ou com taxa de valor baixo, incluindo pré-vestibular comunitário, ou c) Sim, curso preparatório pago; 4) Em qual município você morava ao optar, no vestibular/SISU, pelo Curso de Direito/UFF? (resposta aberta); 5) Você permanece morando no mesmo município, atualmente? (com as possíveis respostas: a sim; b) Não, ao longo do curso, mudei-me com minha família (pais, casamento, união estável etc.); c) Não, ao longo do curso, mudei-me para morar sozinho; e d) Não, ao longo do curso, mudei-me para morar com outras pessoas (ex. república estudantil); 6) Exerce alguma ocupação além dos estudos? (com as possíveis respostas: a) Não, sou estudante em tempo integral; b) Sim, faço estágio extraoficial não remunerado; c) Sim, faço estágio extraoficial remunerado; d) Sim, faço estágio oficial em instituição pública (MP, Defensoria, Juizado etc.); e) Sim, faço estágio oficial em escritório de advocacia; f) Sim, trabalho em órgão público (servidor ou terceirizado); g) Sim, trabalho em empresa privada com carteira de trabalho; h) Sim, sou profissional liberal e/ou trabalhador informal; i) Prefiro não responder a esta pergunta; $h$ ) Outros); 7) Você cursou outra graduação antes de se matricular no Curso de Direito da UFF? (com as possíveis respostas: a) Não; b) Sim, cursava graduação em Direito em instituição particular, com financiamento estudantil; c) Sim, cursava graduação em Direito em instituição particular, sem financiamento estudantil (FIES); d) Sim, cursava graduação em Direito em outra universidade pública; e) Sim, na própria UFF, e me graduei em outro curso; f) Sim, na própria UFF, sem concluir outro curso de graduação; g) Sim, em outra universidade pública, concluindo a graduação em outro curso; h) Sim, em outra universidade pública, sem concluir o outro curso de graduação; j) Sim, em instituição particular (com FIES) concluindo a graduação em outro curso; h) Sim, em instituição particular (com FIES), sem concluir outro curso de graduação; i) Sim, em instituição particular (sem FIES), concluindo a graduação em outro curso; k) Sim, em instituição particular (sem FIES), sem concluir outro curso de graduação; 8) Por que você decidiu cursar Direito? (resposta aberta); 9) Atualmente, o que mais motiva você a concluir a graduação em Direito? (resposta aberta); 10) Com relação aos estudos no ensino médio, você considera o Curso de Direito da UFF (com as possíveis respostas: a) Com maior exigência e rigor nas avaliações; b) Com praticamente o mesmo nível de exigência do Ensino Médio; c) menos exigente que o Ensino Médio; 11) Ao longo do Curso, você obteve algum tipo de apoio financeiro e/ou acolhimento? (com as possíveis respostas: a) Não, e não faria diferença para mim; b) Não, e isto seria importante para minha vida acadêmica; c) Sim, fui/sou bolsista (monitor, iniciação científica, extensão, acolhimento etc.); d) Sim, moradia estudantil; e) Sim, obtive apoio financeiro eventual para participação em eventos acadêmicos, esportivos e/ou culturais; f) Outros). Por fim, também era perguntado no questionário, se o aluno se disponibilizaria para participar de grupo focal com o grupo de pesquisa, o que resultou nos dois grupos focais descritos ao longo do texto.
} 
A pesquisa mapeou 193 ingressantes por ação afirmativa por bônus ou reserva de vaga com matrícula ativa no segundo semestre de 2015. A distribuição dos formulários por via eletrônica obteve 115 respostas para este seguimento. Quanto ao resto da comunidade acadêmica, obteve-se a resposta de 16 professores, 20 servidores/ técnicos, 317 graduandos 5 e 34 pós-graduandos.

Uma vez coletados e sistematizados os dados e as respostas das pesquisas, estes foram discutidos pelo grupo de pesquisa, e levados junto ao Centro Acadêmico Evaristo da Veiga (CAEV - Centro Acadêmico da Faculdade de Direito da UFF) ao Colegiado de Curso da Faculdade, resultando em uma série de discussões com os membros do colegiado, que culminaram na aprovação de ações afirmativas e recomendações com o intuito de incentivar a permanência e as discussões acerca das temáticas de ações afirmativas e racismo na Faculdade.

A observação dos dados coletados possibilitou a identificação de marcas (formas) de silêncio: ausências, apagamentos, não ditos, negações. As ferramentas da Análise de Discurso, presentes nas obras de Eni Orlandi, possibilitam entender que essas manifestações (ou não manifestações) são especialmente significativas, já que são elementos discursivos. Nesse contexto acadêmico, considerado de elite, em que os interesses hegemônicos são perpetuados em especial pela relação entre poder e dominação, é muito possível a compreensão da presença de racismo.

\section{ALGUNS DADOS OBJETIVOS OBTIDOS NAS RESPOSTAS DOS QUESTIONÁRIOS}

A pesquisa coletou e mapeou dados objetivos provenientes dos bancos de dados públicos, da COSEAC-UFF e do SISU/ENEMdoMEC, e fornecidos pela coordenação da Faculdade de Direito da UFF referentes aos estudantes cotistas com matrícula ativa no segundo semestre de 2015.

\footnotetext{
${ }^{5}$ A pesquisa zelou para que fosse obtido um mínimo de respostas para cada período da graduação, de modo a não haver uma contaminação de respostas da pesquisa por muitas respostas de alunos de um período, e menos de outro, uma vez que com o processo gradual de implementação do sistema de cotas, as turmas mais antigas possuem menos cotistas.
} 
Nesse período, 193 estudantes que ingressaram por bônus ou reserva de vagas entre o primeiro semestre de 2013 e o segundo semestre de 2015 permaneciam cursando a Graduação em Direito.

Por meio dos dados provenientes da COSEAC-UFF e do SISU/ ENEM, foi possível mapear a nota de corte de ingresso pela ampla concorrência e por reserva de vagas. Mapeando a nota de corte do SISU entre o primeiro semestre de 2014 e o segundo semestre de 2015, as maiores notas de corte na primeira chamada foram todas da ampla concorrência, sinalizando que essa nota é superior à dos ingressantes por reserva de vagas em geral. Nesse período, a maior nota de corte na primeira chamada da ampla concorrência foi 756,42 pontos no primeiro semestre de 2015 para o turno integral, enquanto a maior nota para reserva de vagas nessa seleção foi 733,10 pontos na modalidade L3 para o turno integral. Já maior nota de corte na primeira chamada da reserva de vagas nesse período foi 741,22 pontos na modalidade L3 no primeiro semestre de 2014 para o turno integral, enquanto a nota de corte para ampla concorrência foi 754,82 pontos nesse processo seletivo. Em contrapartida, a menor nota de corte na ampla concorrência nesse período foi 732 pontos no segundo semestre de 2014 para o turno noturno, enquanto a menor nota de corte para reserva de vagas foi 671,64 pontos foi no segundo período de 2015, modalidade L2.

A diferença de notas para o ingresso por meio da ampla concorrência e da reserva de vagas muitas vezes reafirma a preconcepção de que os estudantes cotistas não teriam condições de acompanhar o curso ou prejudicariam a qualidade dele. Entretanto, apesar da diferença de notas no ingresso pelo SISU, os dados sobre o CR dos ingressantes por ampla concorrência e por reserva de vagas sinalizam que o aproveitamento desses estudantes não diverge ao longo do curso. Nesse sentido, o maior CR médio no primeiro semestre de 2013 foi 8,62 pontos dos estudantes ingressantes pela modalidade $L 3$ de reserva de vagas; no segundo semestre de 2013 foi 9,07 pontos dos cotistas ingressantes pela modalidade L1; no primeiro semestre de 2014 foi 9,04 pontos dos cotistas ingressantes pela modalidade L4; no segundo semestre de 2014 foi 9,01 pontos dos cotistas ingressantes pela modalidade L4; no primeiro semestre de $2015,8,81$ pontos dos estudantes cotistas ingressantes por meio da modalidade L3 
de reserva de vagas. Ao contrário do senso comum, os dados sinalizaram que os estudantes cotistas apresentam maior Coeficiente de Rendimento Médio ao longo de todo o período da pesquisa, apontando que, apesar do déficit na formação básica, os ingressantes por reserva de vagas não possuem um aproveitamento inferior aos ingressantes por ampla concorrência.

Além dos dados sobre as notas de ingresso por meio do SISU e do aproveitamento dos graduandos ao longo do curso, a pesquisa também possibilitou o mapeamento do perfil dos estudantes cotistas, como a idade, a escola em que ele concluiu o ensino médio, se ele realizou algum curso preparatório para o vestibular, a participação em programas de assistência estudantil ou apoio financeiro, entre outros dados. $O$ mapeamento desses dados ocorreu por meio da coleta de informações por meio de questionários eletrônicos com 12 perguntas gerais, respondidos por 115 estudantes cotistas.

A pesquisa possibilitou mapear se os estudantes que ingressaram por ações afirmativas receberam algum tipo de apoio financeiro ou acolhimento estudantil ao longo do curso. Das 115 respostas recebidas, 28 estudantes $(24,3 \%$ ) responderam que não receberam auxílio e que esse apoio não faria diferença para eles; 53 estudantes $(46,1 \%)$ responderam que não receberam auxílio e que esse apoio seria importante para a vida acadêmica deles; 27 estudantes (23,5\%) responderam que receberam apoio, pois receberam bolsa de monitoria, iniciação científica, extensão, acolhimento estudantil etc.; 1 estudante $(0,9 \%)$ respondeu que morava na moradia estudantil; 2 estudantes $(1,7 \%)$ responderam que obtiveram apoio financeiro para participação em eventos acadêmicos, esportivos e/ou culturais; e 13 estudantes (11,3\%) deram outras respostas, como participação em projetos de extensão ou auxílio financeiro dos pais.

O questionário também possibilitou mapear se os estudantes cotistas frequentaram algum curso preparatório para realizar o ENEM/ Vestibular. Das 115 respostas recebidas, 68 estudantes $(59,1 \%)$ responderam que não realizaram qualquer tipo de curso preparatório; 23 estudantes responderam que frequentaram curso preparatório gratuito ou com taxa de valor baixo, incluindo-se pré-vestibular comunitário; e 24 
estudantes $(20,9 \%)$ responderam que frequentaram curso preparatório pago.

A pesquisa também buscou mapear se os estudantes cotistas conciliavam a graduação em Direito com alguma outra ocupação. Das 115 respostas recebidas, 43 estudantes $(37,4 \%)$ responderam que estudavam em tempo integral; 5 estudantes $(4,3 \%)$ responderam que realizavam estágio extraoficial não-remunerado; 13 estudantes $(11,3 \%)$ responderam que realizavam estágio extraoficial remunerado; 18 estudantes $(15,7 \%)$ responderam que realizavam estágio oficial em instituição pública, como o Ministério Público, a Defensoria Pública etc.; 4 estudantes (3,5\%) responderam que realizavam estágio oficial em escritório de advocacia; 24 estudantes $(20,9 \%)$ responderam que era servidor ou terceirizado de órgão público; 3 estudantes $(2,6 \%)$ responderam que trabalham em empresa privada com carteira assinada; 5 estudantes $(4,3 \%)$ responderam que eram profissional liberal ou trabalhador informal; 7 estudantes $(6,11 \%)$ sinalizaram outras respostas.

Em um segundo momento, foi realizada uma pesquisa com os diversos setores da comunidade acadêmica (servidores, professores, graduandos e servidores/terceirizados) buscando observar a percepção desses segmentos sobre diversos aspectos da implementação das ações afirmativas no Curso de Direito da UFF, como o conhecimento da comunidade acadêmica sobre o modelo de reserva de vagas; a percepção sobre a qualidade do curso; sobre a reserva de vagas para monitoria, extensão, PIBIC etc.; sobre a reserva de vagas para ingresso nos cursos de pós-graduação stricto sensu; sobre a reserva de vagas nos concursos para professor efetivo e para as carreiras jurídicas.

Apesar da implementação da Lei de Cotas a partir de 2013, 21,1\% dos servidores/terceirizados e $18,8 \%$ dos professores desconheciam a existência de política de ações afirmativas no Curso de Direito; 31,6\% dos servidores/técnicos e 31,3\% dos professores pensavam que o critério era reserva de vagas apenas para candidatos provenientes de escolas públicas de ensino médio; $26,3 \%$ dos servidores/terceirizados e $43,8 \%$ dos professores acreditavam que o critério existente era de reserva de vagas apenas para candidatos negros, pardos e indígenas; e $21,1 \%$ dos servidores/ 
técnicos e 6,3\% dos professores pensavam que o critério era reserva de vagas somente para candidatos vulneráveis socioeconomicamente.

No que tange às percepções da comunidade acadêmica sobre a alteração do perfil dos discentes da graduação em Direito, a pesquisa mapeou que $30 \%$ dos servidores/terceirizados e $25 \%$ dos professores não identificam qualquer diferença no perfil dos estudantes ao longo dos últimos anos; $20 \%$ dos servidores/terceirizados e $25 \%$ dos professores pensam que há mais estudantes negros do que antes; $35 \%$ dos servidores/terceirizados e $37,5 \%$ pensam que há mais estudantes pobres do que antes; e $15 \%$ dos servidores/terceirizados e $12,5 \%$ dos professores afirmaram que não tinham opinião formada.

Por fim, a pesquisa possibilitou mapear a opinião da comunidade acadêmica sobre outras políticas de ações afirmativas, como a reserva de vagas para bolsas de monitoria, extensão, PIBIC; para o ingresso na pósgraduação e nos concursos públicos para o magistério e para as carreiras jurídicas.

Com relação à reserva de vagas para bolsas no Curso de Graduação (monitoria, extensão, PIBIC etc.), 20\% dos servidores/terceirizados, 56,3\% dos professores e $27,5 \%$ dos estudantes indicaram discordância integral; $40 \%$ dos servidores/terceirizados, $6,2 \%$ dos professores, $42,4 \%$ dos pósgraduandos e $32,5 \%$ dos graduandos responderam que concordam com a reserva apenas para estudantes com renda familiar inferior a um saláriomínimo e meio; $30 \%$ dos servidores/terceirizados, 37,5\% dos professores, $54,5 \%$ dos pós-graduandos e $21,9 \%$ dos graduandos concordam com a reserva de vagas apenas para pobres, indígenas e negros; e $10 \%$ dos servidores/terceirizados e $17,5 \%$ dos graduandos não tem opinião formada.

Com relação à reserva de vagas para ingresso nos cursos de pósgraduação stricto sensu (mestrado e doutorado) vinculados à Faculdade de Direito da UFF, $20 \%$ dos servidores/terceirizados, $50 \%$ dos professores e $34,7 \%$ dos graduandos discordam integralmente com a reserva de vagas; $30 \%$ dos servidores/terceirizados, $20,6 \%$ dos pós-graduandos e $23,4 \%$ dos graduandos concordam com a reserva de vagas apenas para candidatos com renda familiar inferior a um salário mínimo e meio; 
$35 \%$ dos servidores/terceirizados, 50\% dos professores, 55,9\% dos pósgraduandos e $28,4 \%$ dos graduandos concordam que haja reserva de vagas para candidatos pobres, indígenas negros e pardos; $15 \%$ dos servidores/ terceirizados.

Com relação à reserva de vagas nos concursos para professor efetivo do Curso de Direito da UFF, 45\% dos servidores/terceirizados, $50 \%$ dos professores, $23,5 \%$ dos pós-graduandos e $47,5 \%$ graduandos discordam integralmente; $20 \%$ dos servidores/terceirizados concordam que haja reserva apenas para candidatos pobres (renda familiar inferior a um salário mínimo e meio); $12,5 \%$ dos professores, $14,7 \%$ dos pósgraduandos concordam que haja reserva de vagas apenas para candidatos indígenas, negros e pardos; $20 \%$ dos servidores/terceirizados, 37,5\% dos professores, $47,1 \%$ dos pós-graduandos e $25,9 \%$ dos graduandos concordam que haja reserva de vagas para candidatos pobres, indígenas, negros e pardos. Os demais não possuem opinião formada.

Com relação à reserva de vagas nos concursos para carreiras jurídicas (magistratura, Ministério Público, Defensoria Pública, Advocacia Pública etc.), 45\% dos servidores/terceirizados, $43,8 \%$ dos professores, $20,6 \%$ dos pós-graduandos e $43,4 \%$ dos graduandos discordam integralmente. $10 \%$ dos servidores/terceirizados, $12,5 \%$ dos professores, $17,6 \%$ dos pós-graduandos; $35 \%$ dos servidores/terceirizados, $43,8 \%$ dos professores, $50 \%$ dos pós-graduandos e $27,8 \%$ dos graduandos concordam que haja reserva de vagas para candidatos pobres, indígenas, negros e pardos. Os demais não possuem opinião formada.

\section{RESPOSTAS ABERTAS}

Como já exposto, os questionários distribuídos para todos os seguimentos (graduandos, pós-graduandos, servidores e técnicos e professores) portavam uma pergunta de resposta aberta, a ser respondida livremente. A pergunta proposta era "Qual é a sua opinião sobre reserva de vagas para o Curso de Direito da UFF, em razão de políticas de ação afirmativa ("cotas")?". 
Dos questionários enviados para os graduandos, foram obtidas 320 respostas no total. Para os professores, servidores/técnicos e pósgraduandos, foram obtidas, respectivamente, 15, 20 e 33 respostas. Nesse tópico, abordaremos brevemente ${ }^{6}$ as principais recorrências nas respostas, destacando alguns elementos para a análise. Centraremos a análise nas respostas oferecidas pelos graduandos, uma vez que este seguimento realizou um número muito superior de respostas, que torna a análise mais abrangente e representativa.

Nesse seguimento, das 320 respostas, 281 se mostravam favoráveis à reserva de vagas, 32 se mostraram contra e 7 delas não expressaram qualquer opinião de que fosse possível retirar um posicionamento. Dentre as favoráveis às ações afirmativas, 58 delas apresentaram algum tipo de ressalva à reserva de vagas.

Os argumentos favoráveis às cotas articulam diferentes "estratégias discursivas",7com o objetivo de justificar a existências dessa política pública. Podemos identificar dois principais tipos de argumento em defesa das ações afirmativas, no qual foram agrupados as respostas, os argumentos de "reparação" e os argumentos de "diversidade". Conforme assinala Thula Pires:

O argumento da diversidade admite a adoção de políticas

\footnotetext{
${ }^{6}$ Pretende-se que uma análise mais profunda destas respostas seja alvo de publicação específica.

7 Para a análise, entendemos as respostas como um modo de organização argumentativo, articulando categorias da análise do discurso de matriz francesa. 0 modo de organização argumentativo se baseia em alguns fatores. Basicamente, pode-se dizer que é necessário que exista "[...] uma proposta sobre o mundo que provoque um questionamento, em alguém quanto à sua legitimidade (um questionamento quanto à legitimidade da proposta)." (CHARAUDEAU, 2014, p. 205), além de um sujeito engajado em defender essa proposta e um sujeito-alvo a ser convencido dela. Além disso, toda argumentação parte de "[...] uma busca de racionalidade" que tende a um ideal de verdade quanto à explicação de fenômenos do universo", além de "[...] uma busca de influência que tende a um ideal de persuasão, o qual consiste em compartilhar com o outro (interlocutor ou destinatário) um certo universo de discurso até o ponto em que este último seja levado a ter as mesmas propostas." (CHARAUDEAU, 2014, p. 205). Nas respostas analisadas, veremos que as argumentações têm como tema as ações afirmativas, elaborando diferentes estratégias discursivas para legitimarem um posicionamento de defesa ou repulsa a reserva de vagas. Por estratégias discursiva, entende-se a maneira, consciente ou não, que o discurso se constrói, quais informações e argumentos articula.
} 
de ações afirmativas como mecanismos de garantia da pluralidade em ambientes de ensino, trabalho, repartições públicas, entre outros. É a possibilidade de conviver com as diferenças que avalizaria medidas em processos seletivos, por exemplo. Quando se fala em reparação, por sua vez, defende-se a correção da injustiça gerada pelo legado escravista através de ações públicas voltadas à promoção da igualdade dos negros. (PIRES, 2013, p. 231).

Os argumentos de diversidade, ligados à ideia de que a pluralidade de alunos de diferentes origens causa um ganho para todo o ambiente acadêmico, foram menos recorrentes, sendo encontrados em apenas 25 respostas dos graduandos. Os argumentos ligados à ideia de reparação, ou seja, de que as cotas vêm para reparar uma injustiça histórica ou uma desigualdade presente por motivos sociais ou raciais, são mais presentes, aparecendo em 69 respostas. ${ }^{8}$

A maior parte dos argumentos de reparação analisados se limitava a falar de reparação em um sentido mais amplo, sem especificar exatamente o que estava sendo reparado. Muitas respostas identificam especificamente o déficit educacional brasileiro, colocando como ponto central da reparação o fato de que o ingressante por ações afirmativas em questão não teve direito a uma educação adequada. Essas respostas, em geral, mesmo que favoráveis, identificam nas cotas uma política paliativa, uma vez que o principal problema seria a falta de qualidade das escolas públicas brasileiras.

Menos recorrente que os argumentos que falam da reparação por causa do déficit de ensino foram as respostas que criavam a argumentação da reparação histórica com base em uma dívida histórica que a sociedade tem com o povo negro. Dessas, apenas duas citam explicitamente o passado escravocrata da sociedade brasileira. Algumas poucas respostas articulavam categorias ligadas ao racismo, de modo que a maior parte das

\footnotetext{
${ }^{8}$ A maior parte das respostas, 187 delas não articularam nenhum tipo de argumentação consistente, limitando-se a preencher o campo com afirmações como "sou a favor", "positiva" e "perfeito".
} 
respostas baseadas em reparação histórica não abordava a questão racial inerente às ações afirmativas do sistema de cotas. ${ }^{9}$

Os argumentos de diversidade articulam outras ideias. Um primeiro aspecto das respostas é a percepção de que o Curso de Direito é tradicionalmente um curso elitista, vendo na reserva de vagas uma maneira de alterar esse perfil, sendo interessante notar que várias respostas já identificam nas turmas mais novas, com maior número de cotistas, essas mudanças. As respostas dão a entender que alunos cotistas estariam mais interessados em um aspecto social do Direito, e não teriam apenas interesses individuais e profissionais.

Outra recorrência é a proposição de que a presença de alunos de diferentes origens traria um benefício geral para a universidade. Os cotistas seriam pessoas que trariam suas vivências diferenciadas para o ambiente universitário, de modo a contribuírem para uma produção acadêmica diferenciada, pluralizando o ambiente acadêmico e o tornando mais rico e inovador. A diversidade também seria um elemento de luta contra o racismo e a exclusão dentro do ambiente acadêmico, e contribuiria, com a formação de profissionais e intelectuais negros, pardos e indígenas, ou de classes sociais diversas, para a criação de um mercado de trabalho e uma sociedade mais inclusiva.

Mesmo entre os argumentos favoráveis, como colocado, foram diversas as ressalvas às cotas. A primeira, já apresentada, consiste em ressaltar o caráter paliativo ou temporário das cotas, explicando que, apesar de ser a favor do sistema de reserva de vagas, entende que ele deve ser realizado junto com outras medidas, como o combate à pobreza ou a melhoria do sistema educacional. Importante notar que esses argumentos nunca articulam o racismo como um problema em si, identificando sempre como principal problema a desigualdade socioeconômica. As outras duas ressalvas dentre as respostas favoráveis são a ampla possibilidade

\footnotetext{
${ }^{9}$ De maneira diversa em relação ao argumento que se baseia apenas na debilidade do ensino público, o argumento que tem como base a dívida histórica por causa do passado escravocrata se baseia em aspectos muito mais diversos, como genocídio da juventude negra, baixos salários, encarceramento e violência e racismo. Dessa maneira, aqueles que se baseiam nesse argumento veem nas cotas uma solução para problemas sociais mais profundos e amplos do que a simples equiparação no acesso à universidade. A cota seria uma maneira lutar contra o racismo e a desigualdade racial brasileira.
} 
de fraude às cotas, ${ }^{10}$ e os problemas ligados à permanência dos alunos cotistas, que articulam a ideia de que o simples ingresso desses alunos não garante a sua permanência, que encontra outras dificuldades para continuar na faculdade.

Todas as ressalvas feitas pelas pessoas favoráveis às cotas também estão presentes nos argumentos das pessoas contrárias a elas. Dessa maneira, muitas respostas contrárias às cotas reconhecem os mesmos problemas que os defensores das cotas enxergam, mas simplesmente entendem que as cotas não são um caminho para solucionar esses problemas.

Das respostas contrárias, dois são os elementos centrais. 0 primeiro deles é a identificação do principal problema a ser combatido. Este seria a desigualdade social, que seria resolvida com políticas públicas de combate à pobreza, e por um ensino básico de qualidade. Dessa maneira, o debate racial em geral não é citado, e quando é citado, é citado em subordinação à questão social. Resolvendo um, se resolveria o outro.

A segunda questão central é a ideia de "mérito". Os argumentos contrários às cotas em geral articularam ideias ligadas ao mérito, com base em uma ideia específica de igualdade formal. Todos devem ter condições iguais de ingresso (um vestibular sem reserva de vagas) para que o mérito seja testado.

Interessante notar que uma resposta cita expressamente a oposição a uma "igualdade material sofismática" dos defensores das cotas, de modo a reconhecer a oposição entre os conceitos de igualdade presentes. Na análise das respostas, é possível notar como muitas das respostas favoráveis e contrárias às cotas se articulam com base nos mesmos termos, utilizando apenas interpretações diferentes dos mesmos conceitos. Assim, noções de igualdade formal são levantadas pelos opositores das cotas, enquanto noções de igualdade material são levantadas pelos defensores das cotas, com ideias diferentes de mérito sendo articuladas pelos dois grupos. O debate racial, porém, é

\footnotetext{
${ }^{10}$ Como já dito, a pesquisa foi realizada antes da instauração da Comissão Verificadora de Cotas pela UFF, que veio para combater estes tipos de fraudes no que tange à reserva de vagas por critérios étnico-raciais.
} 
um recurso argumentativo das pessoas favoráveis as cotas, e é negado pelos opositores, que subordinam a questão aos problemas sociais e econômicos.

A análise das respostas abertas demonstra que, em parte, a constituição desses discursos antagônicos se fundamenta na disputa da significação de alguns conceitos-chave, como "igualdade, mérito, raça, desigualdade social e pobreza". Enquanto os dois primeiros são articulados por ambos os grupos, porém com significados diferentes, os conceitos ligados à raça são basicamente defendidos como relevantes para o debate por aqueles que defendem as cotas. Para o grupo que é contrário as cotas, é possível, então, identificar um "silenciamento da questão racial", que normalmente é colocada como inerente à desigualdade social e à pobreza. Nesse sentido, para os opositores das cotas, desigualdades raciais e racismo seriam causados apenas por motivos de desigualdade socioeconômica e pobreza. Resolvendo-se o problema da pobreza e desigualdade socioeconômica, o racismo estaria automaticamente resolvido. Questões raciais, portanto, seriam um falso problema para essas pessoas, e poderiam ser solucionados por medidas universalistas que combatessem a desigualdade socioeconômica sem se atentar a questões como racismo desigualdade racial. A partir dessa constatação, partimos para algumas reflexões quanto ao silenciamento do debate racial constado por meio da pesquisa.

\section{A MATERIALIDADE DO SILÊNCIO EM UMA PESQUISA}

Um texto é um tecido cujas linhas podem ser constituídas por palavras (se texto verbal) ou outros signos não linguísticos (texto não verbal), sua essência reside no significar. Um texto é uma unidade significativa. E, numa situação comunicativa, seja verbal ou não verbal, os interlocutores comprometem-se, mesmo que inconscientemente, com a significação, com o político, já que um texto é discurso. Deve, assim, ser compreendido como materialização de um processo histórico-ideológico, presente na sua construção, porque toda palavra integra um contexto, por isso tem história. Essa afirmativa é essencial para se interpretar o silêncio, porque "Sem considerar a historicidade do texto, os processos de 
construção dos efeitos de sentidos, é impossível compreender o silêncio" (ORLANDI, 1995, p. 47). Essa unidade de sentido, que sempre diz algo, utiliza determinadas formas/maneiras para dizer, porque o tecido não é apenas produto, mas, sobretudo, processo. Ler um texto é, portanto, um movimento de atribuição de sentido. Deve o leitor atentar não só para o resultado, mas para o como, por que, para que e para quem se diz.

Considerando-se que a ideologia está presente no texto (que é discurso) e que o dizer é um enunciado produzido por um sujeito que é motivado a dizer e, portanto, o dito tem uma finalidade, o mesmo pode ser afirmado quando ao não dizer, ao silêncio, compreendido como elemento comunicativo, portanto, como categoria de sentido.

$\mathrm{Na}$ pesquisa, foi possível identificar formas de não dizer significativas, elementos discursivos que, no contexto de implementação de uma política afirmativa de inclusão social e étnico-racial, podem simbolizar mais que ausência de conhecimento, mas, talvez, não reconhecimento, constituindo-se o silêncio que torna não aparente, o que está presente. É o que podemos evidenciar na fala de um dos entrevistados em entrevista (grupo focal) promovida pelo grupo de pesquisa:

A faculdade de Direito é uma faculdade bem elitista, apesar das exceções, mas é uma faculdade bem elitista, a parte das políticas de ações afirmativas, as pessoas não gostam de tocar no assunto, pelo ao menos eu senti assim, as pessoas da minha turma são ótimas, mas ninguém toca no assunto, as pessoas falam de colocação, políticas de ações afirmativas ninguém toca muito, assim, eu não sei muito bem quem entrou por política de ação afirmativa ... Há comentários, eu já ouvi assim, a maioria não gosta a maioria com quem eu tive contato, mas isso não é verbalizado. (Entrevistado 1 Aluno de Graduação).

Os dados apresentados nas seções 3 e 4 deste artigo demonstram a problemática na recepção das ações afirmativas na Faculdade de Direito. Apesar do número elevado de apoiadores do sistema de reserva de vagas, um número razoável de pessoas discordava da utilização de ações afirmativas para diversas outras áreas da vida acadêmica ou profissional. 
Também foi demonstrado um grande desconhecimento acerca do próprio funcionamento da política de cotas, tanto nas respostas abertas quanto fechadas.

Na construção da pesquisa, a própria dificuldade de obtenção dos dados, uma vez que os formulários foram distribuídos pela internet, demonstraram uma dificuldade na inserção das pessoas no debate sobre o tema. Houve resistência em responder o questionário, e diversos questionamentos sobre o objetivo de pesquisar ações afirmativas.

O silêncio, então, se mostrou como uma maneira de resistência ao debate, na materialização de sentidos específicos sobre a temática. O silêncio se mostrou então como parte integrante da constituição dos discursos, principalmente no que tange à resistência ao debate sobre cotas, e na negação da existência de desigualdades raciais nos questionários abertos, por parte daqueles que eram contrários ao sistema de reserva de vagas.

Nas palavras de Orlandi (1995, p. 48), "Os sentidos são dispersos, eles se desenvolvem em todas as direções e se fazem por diferentes matérias, entre as quais se encontra o silêncio". O silêncio se mostrou como parte constitutiva dos discursos sobre ações afirmativas na universidade, onde os não ditos muitas vezes revelavam tanto quanto o que era dito.

Ora, um índice de $17,5 \%$ de graduandos que dizem não ter opinião formada (opinião silenciada) sobre um assunto relativo a uma importante forma de viabilizar materialmente a trajetória acadêmica de alunos cotistas indica um não reconhecimento de determinadas condições de permanência no curso, específicas dos alunos cotistas (negros e índios, inclusive), uma realidade do outro, sobre a qual não se pensou (ainda?). Contrapor isso ao resultado relativo à reserva apenas para candidatos pobres (índice de 32,5\%), e à área do gráfico (quase imperceptível) ocupada pelos que concordaram com a reserva étnico-racial evidencia o apagamento da participação de negros e indígenas, nesse processo. 0 racismo estrutural explica a não associação desses modos de dizer e não dizer a uma forma de distinção naturalizada e, portanto, não questionada.

Enfim, nessas poucas linhas permitidas pelo espaço de um artigo, é possível afirmar, à guisa de conclusão dessa sessão, que tanto a ausência 
de palavras quanto algumas (muitas) das palavras ditas, como parte de um processo de comunicação, de troca de sentidos entre pessoas. $O$ ato de comunicação (pelo dizer ou pelo silêncio), entendido na perspectiva da função social, é ferramenta de interação pelo discurso, e representa o olhar sobre o mundo, expondo modos de ser e de estar nesse lugar. Identifica o sujeito como ser social. Liga-se à história e à ideologia e aponta, portanto, para uma realidade que se estrutura pelas relações por ela responsável: as relações de poder hegemônico e dominação.

\section{CONSIDERAÇÕES FINAIS}

A pesquisa desenvolvida possibilitou avaliar a mudança do perfil dos estudantes ingressantes na Faculdade de Direito da UFF, desfazendo pré-concepções e ressaltando desafios da comunidade acadêmica e da universidade para combater o racismo e garantir a permanência e inclusão dos estudantes cotistas na universidade. Nesse sentido, apesar de a pesquisa mapear que os estudantes ingressantes por ações afirmativas possuem desempenho acadêmico equivalente aos ingressantes por ações afirmativas, ela também ressalta o desafio para incluí-los nos programas de monitoria, pesquisa, extensão e de auxílio à permanência.

Os dados coletados e sistematizados e as respostas da pesquisa ampliaram a discussão e as ações afirmativas foi objeto de debates nos órgãos colegiados e reuniões departamentais na Faculdade de Direito da UFF. O Colegiado de Curso realizado no dia 21 de junho de 2016 debateu o tema e culminou na aprovação de ações afirmativas e recomendações que buscavam incentivar a permanência e o debate sobre ações afirmativas e racismo na universidade. Na reunião departamental ordinária do Departamento de Direito Processual (SDP) no dia 29 de agosto de 2016 foi aprovada a reserva de vagas da monitoria para os estudantes cotistas. Por unanimidade foi aprovado que o edital de monitoria para o ano de 2017 reservaria $20 \%$ das vagas para os alunos cotistas; e que o edital de 2018 contemplaria a reserva de $50 \%$ das vagas para estudantes cotistas. Nesse sentido, a pesquisa cumpre a sua função social: gera dados, coloca em debate, provoca, revela questões não ditas, embora vitais, e serve 
ao combate contra o racismo e à melhor compreensão da recepção do sistema de reserva de vagas nas universidades públicas.

\section{REFERÊNCIAS}

BRASIL. Lei 12.711, de 29 de agosto de 2012. Dispõe sobre o ingresso nas universidades federais e nas instituições federais de ensino técnico de nível médio e dá outras providências. Brasília, DF, 2012a. Disponível em: http://www.planalto.gov.br/ccivil_03/_ato2011-2014/2012/lei/l12711.htm. Acesso em: 21 ago. 2019.

BRASIL. Ministério da Educação. Portaria Normativa n. 18, de 11 de outubro de 2012. Dispõe sobre a implementação das reservas de vagas em instituições federais de ensino de que tratam a Lei n. 12.711, de 29 de agosto de 2012, e o Decreto n. 7.824, de 11 de outubro de 2012. Brasília, DF. 2012b. Disponível em: http://portal.mec.gov.br/cotas/docs/portaria_18.pdf. Acesso em: 21 ago. 2019.

BRASIL. Decreto n. 7.824, de 11 de outubro de 2012. Regulamenta a Lei $n$. 12.711, de 29 de agosto de 2012, que dispõe sobre o ingresso nas universidades federais e nas instituições federais de ensino técnico de nível médio. Brasília, DF, 2012c. Disponível em: http://www.planalto.gov.br/ccivil_03/_ ato2011-2014/2012/Decreto/D7824.htm. Acesso em: 21 ago. 2019.

CHARAUDEAU, P. Linguagem e discurso: modos de organização. 2. ed. São Paulo: Contexto, 2014.

ORLANDI, E. P. Análise de discurso: princípios \& procedimentos. 8. ed. Campinas: Pontes, 2009.

ORLANDI, E. P. As formas do silêncio: no movimento dos sentidos. Campinas: Unicamp, 1995.

PIRES, T. R. de O. A discussão judicial das ações afirmativas étnico-raciais no Brasil. In: PAIVA, A. R. Ação afirmativa em questão: Brasil, Estados Unidos, África e França. Rio de Janeiro: Pallas, 2013. p. 210-239. 